\title{
¿REPRESENTACIÓN VOLUNTARIA DE LOS DERECHOS INHERENTES A LA PERSONALIDAD?: CONSIDERACIONES PARA UN DEBATE DESDE EL ORDENAMIENTO JURÍDICO CUBANO*
}

\section{VOLUNTARY REPRESENTATION OF PERSONALITY INHERENT RIGHTS? DEBATE CONSIDERATIONS FROM THE CUBAN LEGAL SYSTEM}

Es este un problema que muy pocas veces se ha planteado en nuestra doctrina de una manera frontal, dándose por supuesta la solución que se sobreentiende que es evidente y muy clara. Sin embargo, no es así, como acontece con frecuencia en Derecho con todas las cosas que son aparentemente claras. Luis Diez-Picazo

\section{Jorge Luis Ordelin Font** \\ Fecha de recepción: 04 de junio del 2013 Fecha de aceptación: 05 de octubre del 2013}

\section{Para citar este artículo / To cite this article}

Ordelin Font, Jorge Luis, ¿Representación voluntaria de los derechos inherentes a la personalidad?: consideraciones para un debate desde el ordenamiento jurídico cubano, 127 Vniversitas, 243-279 (2013)

doi:10.1144/Javeriana.VJ127.rvdi

Resultado de investigación dentro de la Maestría en Derecho Civil que el autor cursa en la Universidad de La Habana, Cuba.

* Profesor Instructor de Derecho Civil. Facultad de Derecho de la Universidad de Oriente. Especialista en Derecho Civil y Familia en la Facultad de Derecho de la Universidad de Oriente. Notario público.jlordelin@fd.uo.edu.cu 


\section{RESUMEN}

El presente artículo tiene como principal objetivo fundamentar la posibilidad de concebir la representación voluntaria de los derechos de la personalidad. Por ello a partir de los fundamentos más modernos que conciben a los derechos de la personalidad y la representación voluntaria se pretende justificar la necesidad de esta figura en determinadas condiciones, en las cuales las instituciones como el respeto a la dignidad humana justifican dicho actuar.

Si bien la imposibilidad de la representación de los derechos de la personalidad constituye uno de las concepciones dogmáticas más aceptadas por la doctrina del Derecho civil actual, hoy esta posición va quedando descartada en figuras como las voluntades anticipadas, la cual constituye uno de los principales ejemplos que justifican la posición que defendemos en este trabajo. Más que establecer dogmas el presente artículo constituye un llamado a la reflexión.

Palabras clave autor: Representación voluntaria, derechos inherentes a la personalidad, disponibilidad.

Palabras clave descriptor: Teoría legal, derechos civiles, régimen jurídicoCuba, derecho comparado. 


\section{ABSTRACT}

This paper was written in order to support the possibility of conceiving voluntary representation of personality rights. Thus, from the most modern basics conceiving personality rights and voluntary representation, it is intended to justify the need of this figure in certain conditions, whereby institutions such as respect for human dignity justify such action.

While the impossibility of representing the rights of personality is one of the most accepted dogmatic conceptions by the current doctrine of civil law, this position is becoming today ruled in figures such as living wills, which is one of the main examples justifying the stance we advocate in this paper. Rather than establishing dogmas, this article is a call to reflection.

Keywords author: Voluntary representation, inherent personality rights, availability.

Keywords author: Legal theory, civil and political rights, legal system-Cuba, comparative law.

\section{SUMARIO}

INTRODUCCIÓN.- I. LOS DERECHOS DE LA PERSONALIDAD. UN MEDIO PARA LA REALIZACIÓN DE LOS VALORES DE LA PERSONA INDIVIDUAL.- A. Los derechos humanos y los derechos de la personalidad. Dos conceptos, un mismo fin.- II. FUNDAMENTOS PARA CONCEBIR LA DISPONIBILIDAD PARCIAL DE LOS DERECHOS DE LA PERSONALIDAD. NATURALEZA JURÍDICA E INTERÉS JURÍDICO PROTEGIDO.- $A$. La dignidad humana: entre la autonomía de la voluntad y el desarrollo de los derechos de la personalidad.- B. La disponibilidad parcial de los derechos de la personalidad.- III. LA REPRESENTACIÓN DE LOS DERECHOS DE LA PERSONALIDAD, ESPECIAL REFERENCIA EN LOS CASOS DE LAS VOLUNTADES ANTICIPADAS.- CONSIDERACIONES FINALES. 


\section{INTRODUCCIÓN}

La representación voluntaria de los derechos de la personalidad ha sido, y continúa siendo, uno de los temas menos tratado por la doctrina jurídica tanto en Cuba como en el extranjero. Ello motivado - en gran medida - por el hecho de dar por sentado que esta es imposible, siendo además una de las afirmaciones más categóricas que en las ciencias jurídicas se han esgrimido. En pleno siglo XXI, cuando la humanidad en sí misma se replantea los cánones tradicionalmente aceptados, y con ellos los de las ciencias jurídicas, sale a la luz la necesidad de una relectura de estas instituciones acorde a principios y valores que constantemente se están redefiniendo, para responder a situaciones coyunturales desde ámbitos más complejos que trascienden las peculiaridades de la ciencia, como los que significan la dignidad, la bioética, el pluralismo o los propios derechos de la personalidad, por solo mencionar algunos ejemplos.

En fecha tan temprana como 1972, el ilustre jurista Luis DiezPicazo, afirmaba la necesidad de matizar la inadmisibilidad de la representación de los derechos de la personalidad siempre y cuando el carácter personalísimo de los mismos no fuera estricto y se tratare de poderes especiales ${ }^{1}$. Ciertamente, la diversidad de contenidos y coyunturas de aplicación diferentes ${ }^{2}$ hacen prácticamente imposible establecer directrices generales sobre cómo puede operar la representación voluntaria de estos derechos. Su carácter excepcional nos impide ofrecer respuestas acabadas cuando tenemos más preguntas que respuestas, sin embargo, sustentados en la naturaleza jurídica de los derechos de la personalidad, la posibilidad de disponer parcialmente de estos y el respeto al desarrollo de la dignidad humana, pretendemos ofrecer los fundamentos que, desde nuestro juicio, pueden hacer viable la representación de los derechos de la personalidad en el ordenamiento jurídico cubano. Queda pues, abierto el debate.

\footnotetext{
1 Luis Diez-Picazo, La representación en el Derecho Privado, Civitas, Madrid, 91 (1979).

2 Por ello hemos decidido explicar la representación de los derechos de la personalidad desde el derecho a la integridad física que se pone de manifiesto en las voluntades anticipadas.
} 


\section{LOS DERECHOS DE LA PERSONALIDAD. UN MEDIO PARA LA REALIZACIÓN DE LOS VALORES DE LA PERSONA INDIVIDUAL}

Como es bien conocido, el término "persona" era utilizado entre griegos y romanos para identificar la máscara usada por los actores para hablar, ocultándose detrás de un semblante sin gestos. Sin embargo, desde el punto de vista jurídico, la persona constituye el ente sustantivo del ordenamiento jurídico, al cual se le reconoce capacidad para ser titular de derechos y deberes, no coincidiendo con el término hombre o ser humano, pues este término abarca también a entidades ficticias creadas por el propio ordenamiento jurídico para intervenir en el mismo.

Para hallar una identidad entre los términos "ser humano" y "persona" en sentido jurídico, debemos delimitar el concepto de persona natural. Este comprende a la persona física, individual, humana, en el contexto del ordenamiento jurídico, el que le reconoce capacidad para ser sujeto de derechos y obligaciones, pero es además portador de atributos y cualidades que tipifican su dignidad humana y que han de ser reconocidos por el derecho ${ }^{3}$. Consustancial con este término, se define entonces a la personalidad jurídica como uno de los elementos de la unión que encierra el concepto de persona, la cualidad jurídico-formal, el hombre como sustrato y los derechos y obligaciones contenidos en la norma como poder jurídico4, que en palabras de Valdés Díaz se traduce en la cualidad abstracta que tiene la persona, como ente, para adquirir derechos y obligaciones, reconocida por el ordenamiento jurídico y se ostenta por el solo hecho de ser persona independientemente de las cualidades o características físicas o psíquicas del individuos.

3 Caridad del Carmen Valdés Díaz, Derechos inherentes a la personalidad, Bioética y Derecho de Familia en IUS, Revista del Centro de Investigaciones, Instituto de Ciencias Jurídicas de Puebla, México, Año IX, No 16, Abril 2005.

4 Justina M. Díaz, Derechos personalísimos en la Bioética, Facultad de Derecho de la Universidad de Buenos Aires. disponible en portalacademico.derecho.uba.arl...lasig_catedras_doc_curr.asp? Consultado el 12 de febrero de 2012

5 Caridad del Carmen Valdés Díaz, Derechos inherentes a la personalidad..., op. cit. En contra de la utilidad del término personalidad se ha pronunciado Fernández Sessarego, para quien la personalidad no es más que la manifestación fenoménica de la persona, su exteriorización en el mundo, su peculiar "manera de ser, la forma de manifestarse la persona ante el Derecho, considerando el término innecesario. El autor opina que su utilización sustituye otro término que es el pertinente como es el de la "capacidad de ejercicio". Cfr. Carlos Fernández Sessa- 
La persona, y por tanto la personalidad, constituyen un prius respecto del derecho, o sea, la persona existe con independencia del derecho y tiene esa consideración desde el momento en que nace con vida. Sin embargo, la personalidad del individuo no coincide con el término personalidad jurídica, como tampoco coincide el término ser humano y persona natural para el derecho. Mientras la primera es expresión de individualidad auténtica, profunda e íntima de la persona, la segunda constituye una categoría jurídica, que al decir de Recasens Siches es la dimensión que este tiene de común con otros sujetos jurídicos que la hace susceptible de positivización en la abstracción de la norma jurídica. ${ }^{6} \mathrm{Al}$ respecto el propio autor ha esgrimido "[...] ser persona en derecho, o ser persona de derecho, no es lo mismo que ser un hombre individual, que ser persona en sentido radical y plenaria, es decir, que ser el individuo"?.

¿Cuál es entonces el papel del derecho en relación con la persona y su personalidad? ¿Cuál es el fin de este reconocimiento de la

rego, Persona, personalidad, capacidad, sujeto de derecho: Un reiterado y necesario deslinde conceptual en el umbral del siglo XXI. Disponible en http://www.revistapersona.com.ar/ Persona24/24FernandezSessarego.htm ( 9 de febrero del 2012). Si bien podemos afirmar que a nuestro juicio, el eminente profesor no distingue la personalidad de la personalidad jurídica y este último término de su relación con el de capacidad jurídica, es cierto que este constituye uno de los temas en los que aún no existe un consenso en la doctrina. Por ejemplo, para el profesor Castán Tobeñas capacidad es sinónimo de personalidad, pues implica aptitud para derechos y obligaciones, o lo que es igual para ser sujeto, activo o pasivo, de relaciones jurídicas. Vid. José Castán Tobeñas, Derecho Civil español, común y foral, tomo 1, Reus, Madrid, 160 (1987). Por su parte, para Márquez Ruiz el término personalidad jurídica es previo al de capacidad jurídica, la personalidad es un quid simple, mientras la capacidad es un quantum y, por tanto, es susceptible de ser medida en grados. Se puede ser, como persona, más o menos capaz, pero no se puede ser más o menos persona. Persona se es o no se es: total, radicalmente. Cfr. José Manuel Márquez Ruiz, "Comienzo y fin de la personalidad”, en Noticias Jurídicas, abril del 2004. Disponible en: www.sentencias.jurídicas.es (4 de enero del 2010). La doctrina nacional, por su parte, considera que si bien la capacidad jurídica se relaciona estrechamente con la personalidad, aquella es manifestación inmediata de esta última; la primera constituye manifestación de la aptitud para ser sujeto de derecho y obligaciones en potencia, mientras la segunda es esta manifestación en una relación jurídica concreta. Cfr. Caridad del Carmen Valdés Díaz, Acerca del ejercicio de las personas discapacitadas. Una aproximación desde la realidad cubana. Disponible en www.revistapersona.com.ar/Persona58/58Valdes.htm $(9$ de febrero del 2012); María Milagrosa Díaz Magrans, "La persona individual", en Derecho Civil. Parte General, Caridad del C. Valdés Díaz (coord.), Félix Varela, La Habana, 106 (2002).

6 Recordemos que el término personalidad jurídica no es privativo de los seres humanos, se les reconoce también a otros sujetos creados por el propio ordenamiento jurídico. En este sentido, el propio autor ha expresado "tan artificial es la personalidad jurídica que se atribuye al sujeto individual, como aquella que se concede a la entidad colectiva. Al decir artificial quiero expresar construida por el Derecho, dimanante del Derecho, y no dada aparte de él". Apud. Luis Recasens Fiches, Vida humana, Sociedad y Derecho, Biblioteca Virtual Universal (2003); Luis Recasens Fiches, Estudios de Filosofía del Derecho, tomo I, Unión Tipográfica Editorial Hispano-Americano, México, 380 (1946).

7 L. Recasens Fiches, Estudios..., op. cit., 381. 
personalidad jurídica del hombre? La respuesta parte de la posición que adoptemos en torno a la disyuntiva de si el derecho y el Estado son para el hombre o si, por el contrario, el hombre es para el derecho y el Estado ${ }^{8}$.

Coincidimos en reconocer que el derecho constituye un medio para la realización de los valores de la persona individual. La personalidad jurídica constituye la imputación normativa de aquella, donde necesariamente confluyen, por ser inescindibles, los elementos comunes al resto de los hombres - entre ellos los derechos innatos - y la individualidad de la persona. La personalidad jurídica constituye una categoría que permite el desarrollo en el ordenamiento jurídico de la persona y su personalidad y debe velar por el desarrollo de la misma más allá del estrecho margen impuesto por la norma. Para ello toma como referencia el carácter tridimensional del derecho, en el que convergen normas, valores y realidad social.

En este orden de ideas, nos adherimos a la posición defendida por De Castro y Bravo, quien veía a la persona como un ser ético, teleológico, perfecto en sí mismo y portador de una dignidad inalienable, a quien se reserva la titularidad de derechos subjetivos, no para constituir o reconocer a la persona, sino para su respeto, base y justificación de los mismos ${ }^{9}$.

Conforme a esta posición, podemos concluir que el derecho no crea a la persona, al ser humano. Este no es una abstracción formal o un concepto jurídico, sino una realidad social que exige su positivización, la cual nunca podrá limitar ni ir en detrimento de su carácter racional y dignidad irrepetible; al contrario, se erige para constituirse en deber de respeto y protector de su esfera jurídica. Con este propósito, el ordenamiento jurídico establece disímiles vías para garantizar el fin ontológico del hombre. Ello ineludiblemente conllevó, como seguidamente analizaremos, al reconocimiento en la esfera del derecho civil, de los denominados derechos o bienes de la personalidad ${ }^{10}$. La explicación de cuáles son estos derechos

8 Las llamadas posturas antitéticas e inconciliables, personalismo y transpersonalismo. Cfr. L. Recasens Fiches, Vida humana..., op. cit.

9 Cit. Pos Alonso Pérez Mariano, "Reflexiones sobre el concepto y valor de la persona en el Derecho civil de España" en Anuario de Derecho Civil, tomo XXXVI, fascículo III, octubrediciembre 1983.

10 Sobre el término existen diversos criterios doctrinales, así por ejemplo De Castro los denominó 
de la personalidad — como preferimos denominarlos-, que se congregan bajo esta denominación, responde a las más disímiles concepciones, aunque todas coincidan en determinar como su objeto aquellas manifestaciones físicas o espirituales de la personalidad del individuo que se distinguen de este y sobre las cuales el derecho confiere un determinado ámbito de poder ${ }^{11}$.

La concepción de los derechos de la personalidad para nada queda constreñida dentro de los límites que imponen los términos de persona y personalidad en su sentido jurídico. Si bien su ámbito es el derecho, ellos trascienden al mismo y encuentran su fundamento en la dignidad de los hombres, que al unísono es su fin último. Como bien afirmara Recasens Siches, "Quien tiene los derechos y los deberes es el hombre. La personalidad jurídica no es el soporte de estos derechos y deberes, sino su expresión unitaria, bajo la forma de personificación, de aquella parte del orden jurídico — como sistema aparte-que los establece"12.

bienes de la personalidad, sin embargo, la expresión más aceptada es derechos de la personalidad (Santos Cifuentes, Castán Tobeñas, Moisset de Espanés\& Hiruela de Fernández); por su parte, Fernández Sessarego, prefiere hablar de Derechos de las personas. Vid. C. Fernández Sessarego, Persona, personalidad, capacidad..., op. cit., posición que fue positivizada en el Código Civil de Perú de 1984, vid. arts. 3-18, Título II Derechos de la Persona, Sección Primera Personas Naturales, Libro I Derecho de las Personas.

11 Para Lacruz Berdejo \& Rivero Hernández, se refieren a la propia entidad e integridad de la persona y a sus manifestaciones físicas y espirituales vistas desde una perspectiva distinta a la de la persona en cuanto sujeto de derecho, cit. pos José Javier Hualde Sánchez, "Los derechos de la personalidad", en Manual de Derecho Civil, Introducción y derecho de la persona, Lluis Puig I. Ferriol et ál., Marcial Pons, Ediciones Jurídicas y Sociales, Madrid, 333 (1997). Por su parte, De Castro expone que con dicha expresión define una misma realidad, los valores del hombre como persona Vid., Federico De Castro, "Los llamados derechos de la personalidad. Dos estudios provisionales", en Anuario de Derecho Civil, tomo XII, fascículo IV, Instituto Nacional de Estudios Jurídicos, Servicio de Publicaciones, 1237, (oct.-dic., 1959); Castán Tobeñas define como tal "los derechos que se ejercitan sobre la propia persona o sus cualidades o atributos, asegurando el goce de nuestros bienes internos, de nuestras energías físicas y espirituales", Vid. J. Castán Tobeñas, Derecho Civil español, común y foral, op. cit., 357. En la doctrina nacional, Díaz Magrans los definió como aquellos poderes o facultades que la norma otorga a la persona solo por ser tal y sobre bienes relacionados con su propia naturaleza y que le son intrínsecos, como la vida, el honor, la propia imagen, el nombre, entre otros. Vid. M. M. Díaz Magrans, "La persona individual", op. cit., 135. En similar sentido Álvarez-Tabío Albo, los definió como el conjunto de bienes que son tan propios del individuo, que se llegan a confundir con él, y constituyen las manifestaciones de la personalidad del propio sujeto. Son una institución puesta al servicio de la persona para hacer valer su dignidad como tal. Vid. Ana María Álvarez-Tabío Albo, Los derechos inherentes a la personalidad, en Boletín ONBC, No. 16 (jul.-sep. 2004).

12 L. Recasens Fiches, Estudios..., op. cit., 380. 


\section{A. Los derechos humanos y los derechos de la personalidad. Dos conceptos, un mismo fin}

Hablar de derechos de la personalidad y su significación en la realización de los valores del hombre, significa adentrarnos en su ya inmemorable relación con los derechos humanos.

El siglo XVII se caracterizó por constituir, en palabras de Fassó, la plena afirmación del racionalismo, lo que trajo consigo que no se reconocieran otras fuentes de conocimiento más allá del intelecto humano ${ }^{13}$. El origen de los derechos humanos, en su concepción actual, hay que buscarlo en esta corriente filosófica y su concreción en las declaraciones de derechos (bills of rights), tanto de la Revolución Americana, con la Declaración de Independencia del 4 de julio de 1776, como, posteriormente, en la Declaración de los Derechos del Hombre y del Ciudadano redactada por la Asamblea Constituyente francesa en 1789. Ambos documentos, sin dejar de ser expresiones de concepciones propias a sus tradiciones jurídico-políticas, declaran la protección de derechos innatos al hombre, garantizando al individuo el goce de los derechos que el pensamiento de la época consideraba naturales, es decir, los poseídos por el hombre en base a su propia esencia, con independencia de su pertenencia o no a una determinada clase social.

Como expresiones del momento histórico concreto en el cual fueron enarbolados, a partir de la lucha de la burguesía por legitimar su poder y su lucha contra el absolutismo monárquico, la adopción de estos derechos innatos se establece en las Cartas Constitucionales o Constituciones, como documentos programáticos en los cuales quedaba reflejado el pacto social que daba origen al Estado, y donde quedaban delimitados los derechos de los ciudadanos con respecto a estos. De ahí que en su mayoría sean reconocidos como derechos de abstención.

Este reconocimiento dentro de los textos constitucionales ha traído consigo la disquisición entre los llamados derechos humanos y los derechos morales. Distinción acusada a partir de la puesta en práctica del positivismo y su enconada lucha por distinguir el derecho de la moral. Sin embargo es hoy aceptado, aunque no de

13 Guido Fassó, Historia de la Filosofía del Derecho, Tomo 2, La Edad Moderna, $3^{\text {a }}$ ed., Ediciones Pirámide, Madrid, p. 81 (1982). 
forma unánime, que el concepto derechos humanos, comprende tanto las facultades reconocidas por el ordenamiento jurídico como cualquier otra cualidad o propiedad perteneciente al hombre, independientemente del reconocimiento normativo ${ }^{14}$.

No obstante, el derecho constitucional y el penal se erigieron como los soportes de la protección de los reconocidos derechos humanos, quedando relegado el derecho civil a las cuestiones puramente patrimoniales. Sin embargo, una revisión del objeto del estudio del derecho civil, a partir del pasado siglo, define a la persona como objeto de este, y por tanto, a la personalidad y sus derechos como temáticas obligadas de dicho tratamiento normativo. Con ello quedaba relegada la concepción estrictamente patrimonialista de esta rama del derecho.

Sin lugar a dudas, el tratamiento por la doctrina civilista de los derechos de la personalidad trajo consigo la delimitación de estos derechos frente a los derechos humanos. Para Rogel Vide, estos derechos tienen similar objeto, pero con orígenes históricos diversos, con emplazamientos diferenciados dentro del derecho como sistema, que se mueven en ámbitos no exactamente coincidentes y que se protegen desde perspectivas distintas. De esta forma, los bienes de la personalidad — como este autor los nombra — constituyen en el ámbito del derecho privado los derechos de la personalidad, y en el ámbito del derecho público, dígase constitucional, se denominan derechos fundamentales y libertades públicas ${ }^{15}$; similar posición

14 Por su parte, la doctrina española ha preferido delimitar el término "derechos fundamentales" para designar las facultades concedidas o garantizadas por el derecho positivo. Posición con la cual no toda la doctrina ha estado conteste. Por ejemplo, Pérez Royo, considera que los derechos fundamentales son los derechos naturales democráticamente constitucionalizados acompañados de las notas distintivas de eficacia directa y vinculación a todos los poderes públicos, indisponibilidad por el legislador, contenido esencial, control judicial y control de constitucionalidad. Igualmente, reconoce que todos los derechos reconocidos en la Constitución española de 1978 son derechos fundamentales y tienen sustancialmente la misma naturaleza, pero no el mismo estatuto constitucional. Vid. J. Pérez Royo, Curso de Derecho constitucional, 4a ed., Editorial Marcial Pons S.A., Madrid (1997); en similar sentido, José Asensi Sabater, para quien la primera característica de los derechos fundamentales es su constitucionalización. Vid. José Asensi sabater, Constitucionalismo y Derecho constitucional - Materiales para una Introducción, Tirant lo Blanch, Valencia (1986); en contra, y por ende a favor del término "derechos humanos" y todo lo que ello implica, vid. Danelia Cutié Mustelier \& Josefina Méndez López, El sistema de garantías de los derechos humanos en Cuba, Santiago de Cuba (2001).

15 Vid. C. Rogel Vide, "Origen y actualidad...", cit. pos C. del C. Valdés Díaz, "Comentario al artículo 38 del Código Civil”, en Comentarios al Código Civil cubano, Tomo I, Disposiciones generales, Libro I, Relación jurídica, Leonardo B. Pérez Gallardo (dir. en prensa). En similar sentido, se pronuncia J. J. Hualde Sánchez,, "Los derechos de...”, op. cit., 332. 
adoptan dentro de la doctrina nacional autores como Rapa Álvarez y Valdés Díaz.

Para el primero de los autores anteriormente mencionados, aunque estos derechos están reconocidos en el texto constitucional, han recibido un especial reconocimiento legislativo en el Código Civil, donde no se contemplan como derechos derivados de las relaciones entre sus titulares y las entidades públicas como el Estado - pues de estas se ocupan otras ramas de la legislación como la constitucional o la penal—, sino que estos derechos se originan de relaciones de sujetos que actúan en plano de igualdad aunque protegen los mismos intereses en que se fundamentan las libertades públicas ${ }^{16}$. Por su parte Valdés Díaz, si bien reconoce que los derechos fundamentales enuncian clásicamente una relación individuo-Estado y pertenecen al ámbito del derecho público - mientras que los derechos de la personalidad se mueven en el ámbito de las relaciones interpersonales y se resguardan mediante mecanismos propios del derecho civil, esto es, mediante la exigencia de responsabilidad jurídica civil cuando tales derechos sufren una intromisión ilegítima o cualquier menoscabo, ya sea una afectación con incidencia económica o puramente moral-, también reconoce, citando a De Domingo Pérez, que esta noción clásica no se mantiene incólume, pues hoy se entiende que los derechos fundamentales tienen también eficacia horizontal, pudiendo quedar obligados por ellos no únicamente el Estado, sino además los particulares ${ }^{17}$.

Por su parte, Llamas Pombo sostiene que dentro de la amplia gama de derechos fundamentales o humanos hay una especie que son los derechos de la personalidad, destacados por unas características concretas, siendo la fundamental su inherencia e inseparabilidad del hombre como sustancia racio-corporal ${ }^{18}$.

Podemos afirmar que, si bien los derechos de la personalidad mantienen una identidad con respecto a los derechos humanos o

16 Vicente Rapa Álvarez, La relación jurídica. Categoría esencial en el nuevo Código Civil, VI Revista Jurídica, No. 19, 136 (abr.-jun., 1988).

17 C. del C. Valdés Díaz,, "Comentario al artículo 38...", op. cit., 9. Sobre la posibilidad de que los derechos fundamentales sean también tomados en cuenta en la relación entre particulares, vidJesús. Alfaro Águila-Real, "Autonomía privada y derechos fundamentales", en Anuario de Derecho Civil, Tomo XLVI, fascículo I (ene.-mar., 1993).

18 Eugenio Llamas Pombo, cit. pos Gisela María Pérez Fuentes, Evolución doctrinal, legislativa y jurisprudencial de los derechos de la personalidad y el daño moral en España, Revista de Derecho Privado, No. 8, Instituto de Investigaciones Jurídicas de la unam, México. 
fundamentales, esta no es total en todo su contenido, ni tampoco en los medios de protección que el ordenamiento jurídico ofrece para cada uno. Por ejemplo, no podemos decir que existe una identidad de contenido entre los derechos de la personalidad y los humanos de la segunda y tercera generación, de naturaleza y titularidad totalmente diferentes, lo que no indica que la identidad no exista en cuanto a la naturaleza de los mismos. Coincidimos con Valdés Díaz al afirmar que: "[...] no se trata de conceptos excluyentes ni existe entre ellos una absoluta y tajante delimitación, cual si pertenecieran a compartimentos estancos incomunicables. Se trata de derechos entre los cuales debe fluir una constante interconexión, una recíproca influencia, por cuanto ambos pretenden proteger los bienes supremos del hombre"19. En similar sentido, López Jacoiste afirma "aun asumidos como derechos fundamentales, los derechos de la personalidad están llamados a permanecer en continua dialéctica argumental. Dialéctica concerniente al contenido, al alcance de su respectiva área y a las restricciones o expansiones de la misma. El carácter de derechos fundamentales no los encasilla en moldes cerrados, pues mantienen su natural dinamismo pugnaz y expansivo"20.

De lo anteriormente expuesto podemos concluir que si bien no existe una coincidencia entre los derechos fundamentales y los derechos de la personalidad, no podemos negar la identidad que existe entre sus fines y el objeto de protección, más allá de los ámbitos de protección y ejercicio en pos de la realización personal del hombre y la realización de su dignidad. Lo cual será válido para, a partir de una interpretación integradora, determinar un contenido esencial de cada derecho, o al menos de los presupuestos que permitan su determinabilidad.

En el ordenamiento jurídico cubano, si bien la relación entre los derechos de la personalidad y los derechos humanos queda en principio debidamente "enunciada", la deficiente técnica legislativa empleada en la redacción de la norma sustantiva civil, posterior al texto constitucional cubano, impide lograr la pretensión deseada de encontrar desde el ámbito constitucional una definición de un

19 C. del C. Valdés Díaz, "Comentario al artículo 38...”, op. cit.

20 José Javier López Jacoiste, "Una aproximación tópica a los derechos de la personalidad”, en Anuario de Derecho Civil, Tomo XXXIX, fascículo IV, p. 1115 (oct.-dic., 1986). 
contenido esencial para estos derechos que permita el ejercicio y aplicación de estos.

El artículo 38 del Código Civil cubano realiza una remisión expresa a los derechos inherentes a la personalidad consagrados en el texto constitucional. Sin embargo, la ausencia de una regulación expresa en el texto constitucional de los derechos inherentes a la personalidad ha provocado los más enconados debates sobre el régimen jurídico de los mismos en nuestro ordenamiento. Esta disquisición ha sido brillantemente superada a partir del consenso existente entre la jurisprudencia y la doctrina nacional, al considerar protegidos estos derechos, más allá de la deficiente técnica legislativa $^{21}$. De ahí que en esta relación entre los derechos humanos y los derechos de la personalidad en el ordenamiento jurídico cubano, solo nos detendremos en precisar que:

Dentro del ordenamiento jurídico cubano, el respeto y desarrollo de la dignidad se convierte en el fundamento del reconocimiento de estos derechos. Este valor básico y supremo es el legitimador del resto de los derechos y de la exigencia de su respeto. Tiene un reconocimiento expreso en el texto constitucional tanto en su preámbulo como en el artículo 9 a) tercera pleca ${ }^{22}$. La disyuntiva entonces, no

21 Una mera búsqueda de los derechos de la personalidad en el texto constitucional nos conlleva a concluir que en el mismo no existe una tipificación de los derechos inherentes a la personalidad. De ahí que sea una pregunta siempre latente, el por qué el legislador del Código Civil, realizó una remisión al texto constitucional cuando al ser este anterior a aquel, era evidente que dichos derechos no se encontraban expresamente reconocidos; posición que es a su vez más contradictoria cuando se tienen en cuenta los anteproyectos del Código Civil. En este sentido, un análisis de los anteproyectos del Código Civil constata una especie de retroceso en la regulación de estos derechos en la norma sustantiva civil cubana. De esta forma el capítulo III del anteproyecto del Código Civil de 6 de febrero de 1979 se nombraba "Derecho de protección", y en su sección primera regulaba todo lo concerniente a los derechos de integridad de la persona, el nombre, la imagen; en correspondencia con ello, la exposición del anteproyecto del Código Civil cubano en su edición del 27 de agosto de 1979 explicaba como novedad del mismo el dedicar un capítulo a los derechos de protección de las personas individuales, tanto en lo que se refiere a su integridad física como los derechos al nombre, a tener un domicilio, a la imagen, la cesión de órganos, tejidos o partes del propio cuerpo de la persona individual viva, siempre que la vida no estuviera en peligro ni el donante tuviera ánimo de lucro. Sin embargo, ya en el anteproyecto de febrero de 1985, si bien se reconocían como derechos inherentes a la personalidad, fundamentalmente, la integridad personal, la libertad, la libertad de conciencia, el nombre, el honor, la propia imagen y los relacionados con la actividad creadora, la redacción del artículo no exponía un contenido esencial sobre estos, sino que solo se limitaba a enunciarlos. Sobre la protección de los derechos de la personalidad en el ordenamiento jurídico cubano, cfr. C. del C. Valdés Díaz, "Comentario al artículo 38...", op. cit., y V. Rapa Álvarez, "La relación jurídica...", op. cit.

22 El preámbulo de la Constitución de la República de Cuba declara que la ley de leyes de la República esté presidida por este profundo anhelo, al fin logrado, de José Martí: "Yo quiero que la ley primera de nuestra República sea el culto de los cubanos a la dignidad plena del hombre". 
se encuentra en el reconocimiento o no de los derechos de la personalidad, sino en el contenido esencial de estos derechos, puesto que si el ordenamiento jurídico reconoce el valor fundamental sobre el que se erigen todos los derechos, reconoce, por una especie de transitividad, todos los derechos de la personalidad. No obstante, la ausencia de un contenido esencial sigue siendo necesaria como límite de los intereses jurídicamente protegibles que permite que estos derechos tengan vida y resulten reales, concreta y efectivamente protegidos ${ }^{23}$.

En materia de lege ferenda, somos del criterio de que cualquier positivización de los derechos de la personalidad debe realizarse a partir de un elevado nivel de abstracción, que permita la adecuación de estos derechos al dinamismo que le es consustancial, según cambien los tiempos. No es posible el reconocimiento concreto de tal derechos, puesto que su protección debe abarcar tanto las manifestaciones actuales como las futuras, encuéntrense estas legalmente reguladas o no; ello posibilita un margen más amplio de ejercicio y efectividad. No podemos olvidar que la persona, a la par que mantiene incólume su identidad, se trasciende de continuo a sí misma y se está haciendo siempre ${ }^{24}$. La formulación abierta significa la regulación del contenido esencial de cada derecho que permita su aplicación flexible en múltiples ámbitos, a la vez que sirve para delimitar el mismo según cada contexto y momento, correspondiéndole a los tribunales a partir de una interpretación progresiva, esencialmente, dibujar los contornos de la figura.

Por su parte, en materia de lege data, la ausencia de este contenido esencial hace bastante compleja la delimitación de un cuantum básico que establezca los límites de cada derecho, no solo ante un menoscabo de estos, sino en la determinación de una posible disponibilidad que pueda ir, o no, en contra de este contenido esencial y

\footnotetext{
Por su parte, el referido artículo 9 inciso a) en su tercera pleca establece como obligación del Estado "garantizar la libertad y la dignidad plena del hombre, el disfrute de sus derechos, el ejercicio y cumplimiento de sus deberes y el desarrollo integral de su personalidad". Este es el criterio seguido por la Sala de lo Civil y Administrativo del Tribunal Supremo "[...] así vemos, como del contenido de la letra del artículo nueve inciso a) pleca tercera de la Constitución de la República de Cuba, se puede estimar refrendado de manera implícita, el derecho al honor en la sociedad cubana; ello, en relación con el artículo treinta y ocho del Código Civil [...]”. Vid. Sentencia No. 513 de 29 de diciembre de 2011. Único considerando. Ponente Acosta Ricart.

23 Sentencia del Tribunal Constitucional español de 8 de abril de 1981, cit. pos J. J. López Jacoiste, "Una aproximación tópica...", op. cit., 1113.

24 J. J. López Jacoiste, “Una aproximación tópica...”, op. cit., 1060.
} 
por ende provoque un perjuicio al respeto de la dignidad humana, dentro de los límites concebidos por el ordenamiento jurídico. No queda otra posibilidad en el ordenamiento jurídico cubano que los tribunales delimiten también este contenido esencial - a pesar de los riesgos que ello implica-; sin embargo, el arbitrio del tribunal siempre estará condicionado por los valores del texto constitucional y del ordenamiento jurídico, la protección a la dignidad humana, en los términos anteriormente expuestos, así como los principios del derecho, las normas de derecho internacional y el momento histórico concreto.

\section{FUNDAMENTOS PARA CONCEBIR LA DISPONIBILIDAD PARCIAL DE LOS DERECHOS DE LA PERSONALIDAD. NATURALEZA JURÍdICA E INTERÉS JURÍDICO PROTEGIDO}

Pero no basta solamente con que se conciba a los derechos humanos y los derechos de la personalidad como medios para la realización de la dignidad de los hombres, sino también es necesario el ejercicio efectivo de estos medios en situaciones jurídicas concretas que permitan esta realización. Por ello, la construcción doctrinal de los derechos de la personalidad se ha erigido sobre tres tesis explicativas de su carácter. Una se orienta hacia la consideración de un derecho general de la personalidad, otra, hacia su encuadramiento como auténticos y diferenciados derechos subjetivos, mientras una tercera prefiere hablar de bienes de la personalidad. Cada una de estas tesis ha tenido, y tiene, enconados detractores, lo que obedece, en palabras de López Jacoiste, a que "no parece que tales asimilaciones puedan ser completas, ni mucho menos que respondan siempre a la estructura y función de los derechos de que se trata. La manera como surgen y se diversifican, el modo de invocarlos y de ponerlos en ejercicio, suscita una metodología que no se circunscribe plenamente a tales concepciones" ${ }^{25}$.

Sin embargo, existe un parcializado consenso doctrinal que trata de explicar, a pesar de sus imperfecciones, la naturaleza jurídica de los derechos de la personalidad como derechos subjetivos ${ }^{26}$,

25 Ídem, 1075 y ss.

26 Se afilian a esta tesis autores como Castán Tobeñas, Santos Cifuentes, Moisset de Espanés 
considerándolos una suerte de especie dentro de esta categoría, puesto existen características que los particularizan, como son el ser innatos al hombre, vitalicios, necesarios, inherentes, irrenunciables y extrapatrimoniales. Estas características implican que el poder concedido por el ordenamiento jurídico se vea limitado, pues en principio nada se puede disponer acerca de su nacimiento, transmisión, extinción y renuncia ${ }^{27}$.

Esta afirmación no es del todo absoluta; una revisión de los fundamentos de la protección de los derechos de la personalidad nos conlleva a afirmar que la disponibilidad parcial de estos derechos, tal como es hoy sostenida por la doctrina, no implica un menoscabo de las características de estos, específicamente en cuanto a su inalienabilidad.

No nos es ajeno el hecho de que el ordenamiento jurídico satisface el interés de los particulares mediante la técnica consistente en atribuirles un poder concreto compuesto por un conjunto de facultades, reales o potenciales, cuyo ejercicio se deja a la libre decisión de su titular. No obstante, lo cierto es que la teoría de los derechos de la personalidad ha sido concebida a partir de la vulneración de estos derechos, y la satisfacción del interés digno de tutela jurídica, solo con la sanción penal o administrativa o la responsabilidad civil extracontractual; sin embargo, en pleno siglo XXI, y a partir de la consolidación de la teoría de los derechos de la personalidad, valdría la pena preguntarnos si no es posible que el interés digno de tutela jurídica, que justifica la protección de estos derechos, se vea satisfecho con un actuar positivo por parte del titular.

\footnotetext{
e Hiruela de Fernández, Díaz Magrans, Álvarez-Tabío Albo, Hualde Sánchez, entre otros. En este mismo sentido, la Comisión encargada del estudio del tema número 2 en el Cuarto Congreso Nacional de Derecho Civil Argentino, celebrado en Córdoba entre los días 22 al 27 de septiembre de 1969, recomendó que en una futura revisión del Código Civil se incorporara a la Sección I del Libro I, un título nuevo que contenga una legislación orgánica sobre los derechos de la personalidad en cuanto derechos subjetivos de carácter especial. Vid. Actas del Cuarto Congreso Nacional de Derecho Civil, 22-27 de Septiembre de 1969, Celebración del Centenario del Código Civil, Tomo I, Córdoba (1971).

27 En contra de los que utilizan este argumento para desvirtuar la naturaleza de derechos subjetivos que presentan estos derechos, Moisset de Espanés e Hiruela de Fernández nos recuerdan que se trata de una falacia argumentativa, de una petición de principio, pues "no es requisito ni recaudo de los derechos subjetivos que el ordenamiento prevea tales cuestiones, de hecho existen derechos patrimoniales que tampoco pueden ser transferidos o cedidos". Cfr. Luis Moisset de Espanés \& María del Pilar Hiruela de Fernández, "Derechos de la personalidad", Artículos de la Academia de Ciencias Jurídicas de Córdoba, Argentina, 12.
} 
Al respecto, Álvarez-Tabío Albo precisa que la condición de los derechos de la personalidad no se manifiesta hasta el momento de la exigencia de responsabilidad que genera la lesión de alguno o varios de los derechos de la personalidad, o del abuso que se haga por un tercero en el ejercicio de alguna de las facultades cedidas en su favor ${ }^{28}$. Por su parte Moisset de Espanés y Hiruela de Fernández afirman "Finalmente, no es cierto que el derecho aparezca recién luego de lesionado; si mediante la indemnización de los daños no se pudiera reparar en especie, el resarcimiento no haría más que reemplazar o sustituir el derecho personalísimo lesionado, como sucedáneo del ataque a un derecho anterior" 29.

Hoy podemos hablar de la posibilidad de la disponibilidad de los derechos de la personalidad como forma de satisfacción de un interés que merece ser digno de tutela por el ordenamiento jurídico, aunque es válido precisar que no todos los derechos de la personalidad pueden ser parcialmente disponibles y en caso de que lo fueren, siempre con la misma intensidad. De hecho, son cada vez más los ordenamientos jurídicos que reconocen la posibilidad de disponer de determinados derechos de la personalidad, ya sea en los propios códigos civiles o en normas complementarias a los mismos. Si bien es dable acotar que, por la forma en que las referidas disposiciones están redactadas, es pertinente interpretar que los actos de disposición constituyen la excepción y no la regla, resultan reiterados los actos de disposición permitidos sobre el propio cuerpo, siempre y cuando no ocasionen una disminución permanente de la integridad física o cuando no sean contrarios al orden público o a las buenas costumbres, la disposición de la imagen y el nombre, y en menor medida sobre la intimidad personal y familiar, a partir del consentimiento del titular o titulares ${ }^{30}$.

28 Ana María Álvarez-Tabío Albo, "Los derechos al honor, la intimidad personal y familiar y la propia imagen como límites a las libertades de información y expresión", Tesis presentada en opción al grado científico de Doctor en Ciencias Jurídicas, La Habana, 22 (2008).

29 Vid. L. Moisset de Espanés \& M. P. Hiruela de Fernández, "Derechos de la personalidad", op. cit., 12 .

30 Por ejemplo, el Código Civil de Perú regula los actos de disposición del propio cuerpo, excepto por disminución permanente de la integridad física o cuando de alguna manera sean contrarios al orden público o a las buenas costumbres, incluyendo la donación de partes del cuerpo y la revocabilidad del referido acto; por su parte, el derecho a la intimidad y familiar puede ser objeto de disposición con el asentimiento de la persona o si esta ha muerto, de su cónyuge, descendientes, ascendientes o hermanos. Igualmente pueden ser aprovechadas la imagen, la voz, comunicaciones, grabaciones, memorias de una persona con su autorización 


\section{A. La dignidad humana: entre la autonomía de la voluntad y el desarrollo de los derechos de la personalidad}

\section{Cualquier posibilidad de disponer parcialmente de los derechos de} la personalidad se haya condicionada por la búsqueda de un equilibrio entre el respeto a la autonomía individual y el respeto a los derechos de la personalidad. En un primer momento, parece que la relación entre ambas categorías se establece por la supremacía del respeto a los derechos de la personalidad sobre el respeto a la autonomía individual. Sin embargo, esta relación encuentra su punto de equilibrio en la dignidad humana.

Esta no solo "supone el valor básico (Grundwert) fundamentador de los derechos humanos que tienden a explicitar y satisfacer las necesidades de la persona en la esfera moral. De ahí que represente el principio legitimador de los denominados «derechos de la personalidad" ${ }^{31}$, sino también implica la capacidad de emitir juicios

y el nombre con fines publicitarios e interés social. Cfr. arts. 6, 7, 9,14, 15, 16, 27, Código Civil de Perú. En el ordenamiento jurídico español, la Ley Orgánica número 1/1982 de 5 de mayo, De protección civil del derecho al honor, a la intimidad personal y familiar y a la propia imagen, dispone que los derechos protegidos en la ley no pueden considerarse absolutamente ilimitados, determinadas entradas en las esferas de estos derechos podrán ser consentidas por el propio interesado, lo que a juicio de la ley no se opone a la irrenunciabilidad abstracta de dichos derechos, pues ese consentimiento no implica la absoluta abdicación de los mismos, sino tan solo el parcial desprendimiento de alguna de las facultades que los integran. La ley exige que el consentimiento sea expreso, y dada la índole particular de estos derechos, permite que pueda ser revocado en cualquier momento. Cfr. arts. 2 y 3, Ley Orgánica número 1/1982 de 5 de mayo, De protección civil del derecho al honor, a la intimidad personal y familiar a la propia imagen. Por su parte, el Código Civil de Portugal reconoce el derecho de toda persona a usar su nombre completo o abreviado, publicación de las cartas confidenciales y memorias con la autorización de sus titulares (lo que es parte del derecho a la intimidad de las personas), e igualmente sucede con el retrato de una persona (derecho a la imagen). En el artículo 81 del propio cuerpo legal se establece que toda limitación voluntaria al ejercicio de los derechos de la personalidad es nula, si es contraria al orden público, lo cual nos hace suponer que si la limitación a partir de la disposición no es contraria a este orden, la misma es permitida. Cfr. arts. 72, 76, 77. 78, 79, 80, 81, Código Civil portugués, Decreto-Ley No. 47 344, de 25 de noviembre de 1966, actualizado por Decreto-Ley 323 de 17 de diciembre de 2001. En similar sentido, el Código Civil brasileño regula que los derechos de la personalidad no pueden ser transmitidos, renunciados, ni ser objeto de limitación voluntaria excepto los casos previstos en la ley, quedando contemplados en este último caso los actos de disposición del propio cuerpo siempre que ello no implique una disminución permanente de la integridad física o contraria a las buenas costumbres, el nombre puede ser utilizado en propaganda comercial con autorización, al igual que sucede con la imagen, la divulgación de escritos, transmisión de palabra o su publicación. Cfr. arts. 11, 13, 18 y 20. Ley No. 10.406, de 10 de enero de 2002, o Novo Código Civil Brasileiro.

31 A. E. Pérez Luño, cit. pos Iñigo de Miguel Beriain, "Consideraciones sobre el concepto de dignidad humana", en Anuario de Filosofía del Derecho, Nueva Época, Tomo XXI (2004); 
morales, la libertad para decidir acerca de las acciones y la posibilidad de generar conceptos abstractos ${ }^{32}$. Encontramos, entonces, que el reconocimiento de la dignidad implica también libertad, que a su vez permite el libre desarrollo de la personalidad y se materializa en el derecho civil en el concepto de autonomía de la voluntad. De ello se colige que el reconocimiento de la dignidad humana conlleva necesariamente el respeto los derechos de la personalidad y de la autonomía individual, que como dos caras de una misma moneda, solo es posible su realización a partir de la conciliación de los intereses comunes con los particulares.

Por ello, en nuestro criterio el ordenamiento jurídico no puede poner objeción a las disposiciones que sobre una esfera jurídica determinada, como son los derechos de la personalidad, pueda realizar el individuo en el ejercicio de su autonomía individual, siempre que los intereses implícitos en este ejercicio no signifiquen un menoscabo de los intereses dignos de tutela jurídica; en otras palabras, siempre que el acto dispositivo no vaya en contra de la dignidad humana y el valor básico y esencial que ella en sí mismo representa, es posible la disposición. La dignidad se erige no solo en el fundamento de la disponibilidad de los derechos de la personalidad, sino también, en la base de la defensa de esos derechos cuando por el propio acto de disponibilidad se menoscaben lo mismos. Se erige en garante del titular que dispone, quien siempre tendrá a la mano este principio para poder defender su esencia humana cuando el acto dispositivo vulnere el derecho de la personalidad.

Por una especie de analogía, podemos entonces concluir que si la dignidad se erige como fundamento de la disponibilidad de los derechos de la personalidad, también lo es en base al principio de la autonomía de la voluntad y la libertad, de la representación voluntaria de algún derecho de la personalidad. El dilema se encuentra en determinar si dentro de este estrecho ámbito de discrecionalidad libre permitida a estos derechos puede ser configurada la representación voluntaria, si tomamos en cuenta que la misma no implica una transmisión, ni renuncia de los derechos de la personalidad; todo lo contrario, brinda la posibilidad de ampliar las posibilidades de su uso y ejercicio efectivo por parte de su titular. Por ello, si es

Ministerio de la Presidencia, Boletín Oficial del Estado, Madrid, p. 187 (2005).

32 I. de M. Beriain, "Consideraciones sobre el...", op. cit., 199. 
posible disponer parcialmente de los derechos de la personalidad, por qué no permitir la representación de los mismos, aunque fuere con un carácter un poco más excepcional y más limitado.

Un último argumento a tener en cuenta para sostener la tesis que venimos sustentando, sobre la posibilidad de la disponibilidad parcial de los derechos de la personalidad y con ello de la representación, nos lo facilita otro aspecto controvertido sobre la regulación de los derechos de la personalidad: la relación entre el poder público y estos derechos. Si bien es cierto que los ordenamientos jurídicos civiles modernos han realizado un reconocimiento de estos, este reconocimiento no es absoluto, existen determinadas limitaciones que justifican la intromisión de los poderes públicos sin que ello signifique un desmedro de la dignidad de su titular y por ende del derecho protegido ${ }^{33}$. Resulta entonces totalmente contradictorio que en determinados supuestos la ley permita la intromisión en los derechos de la personalidad, cuando los intereses públicos sean superiores a los privados, y no se contemple la posibilidad de disponer por parte del propio titular de estos derechos, incluido mediante la representación voluntaria. La vida ha demostrado que tanto en uno como en otro interés los extremos son muy peligrosos, de ahí que exacerbar la supremacía absoluta de los derechos de la personalidad sobre intereses públicos no sea siempre factible, así como la total indisponibilidad de estos derechos pueda conllevar a un menoscabo de la dignidad humana. Por lo general, cualquiera de estas posiciones, defendidas a ultranza, no significa más que imponer valores diferentes a los del titular sin que quepa posibilidad alguna de permitir la diversidad de intereses.

33 Podemos citar el derecho a la imagen de personalidades públicas, el derecho a la intimidad en situaciones excepcionales, las intervenciones corporales en peligro inminente para la muerte, entre otros supuestos. Vid. art. 79.2 Código Civil de Portugal Decreto-Ley No. 47 344, de de 25 de noviembre de 1966, actualizado por Decreto-Ley 323 de 17 de diciembre de 2001. Art. 20, Ley No. 10.406 de 10 de enero de 2002, o Novo Código Civil Brasileiro. Art. 15, Código Civil de Perú. Art. 8, Ley Orgánica número 1/1982 de 5 de mayo, De protección civil del derecho al honor, a la intimidad personal y familiar a la propia imagen. 


\section{B. La disponibilidad parcial de los derechos de la personalidad}

La disponibilidad de los derechos de la personalidad no significa que se limiten dichos derechos por el acto de disposición. Para César Rivera, por ejemplo, con la disponibilidad de estos derechos no hay una renuncia a tales derechos involucrados sino el ejercicio de ciertas facultades ${ }^{34}$; en similar sentido, Clavería Gosálbez afirma, refiriéndose a los actos de consentimiento como manifestación de la disposición de estos derechos, que "concebir tales actos de consentimiento de la intromisión o de la inmisión no como renuncia parcial de esos derechos sino como ejercicio de su contenido positivo" ${ }^{35}$.

Ha sido este último autor quien ha tratado con mayor sistematicidad el tema de los negocios jurídicos de disposición sobre los derechos al honor, la intimidad y la propia imagen. Estudios que si bien quedan constreñidos al ámbito específico de los derechos de la personalidad anteriormente referidos, nada obsta, a nuestro criterio, que los argumentos expuestos puedan ser tenidos en consideración respecto a otros derechos de la personalidad, aunque respetando las peculiaridades de cada uno.

Al igual que César Rivera, este autor sostiene la posibilidad de disponer de dichos derechos a partir de concebir esta posibilidad, no en todo el derecho de la personalidad sino en facetas o aspectos del mismo, como pueden ser la disposición con finalidad económica o el permiso de intromisión, pudiendo ser realizada tanto mediante un acto unilateral, pero también por medio de contratos, con las correspondientes precisiones en cuanto a su contenido y objeto ${ }^{36}$.

Sin embargo, discrepamos del eminente profesor al considerar que en materia de contratos estos negocios no constituyen actos de disposición de los derechos de la personalidad, ni actos de

34 Julio César Rivera, Actos de disposición de los derechos de la personalidad: actuación por los representantes legales, Revista de Derecho Privado y Comunitario, No. 6, Rubinzal-Culzoni, 91 (1994).

35 Luis-Humberto Clavería Gosálbez, "Negocios jurídicos de disposición sobre los derechos al honor, la intimidad y la propia imagen", en Anuario de Derecho Civil, Tomo XLVII, fascículo III, 32 (jul.-sep., 1994).

36 Cfr. L. H. Clavería Gosálbez, "Negocios jurídicos de disposición...”, op. cit. y Luis-Humberto Clavería Gosálbez, "Reflexiones sobre los derechos de la personalidad a la luz de la Ley Orgánica 1-1982, de 5 de mayo", en Anuario de Derecho Civil, Tomo XXXVI, fascículo III (oct.-dic., 1983). 
ejercicio en sentido positivo de esos derechos fundamentales, sino, más bien, ejercicio de una legítima autonomía negocial sobre facultades jurídicas de rango ordinario en el marco de un contrato atípico ${ }^{37}$. Si bien es cierto que la concepción de los derechos de la personalidad como objeto de un contrato puede provocar múltiples objeciones, aun con los argumentos anteriormente expuestos, debemos considerar que el objeto de estos contratos, identificado por el propio profesor, lo constituye la facultad o faceta del derecho. $\mathrm{Y}$ ¿de dónde parten estas si no es del poder que el ordenamiento jurídico reconoce al derecho de la personalidad? Sin este aquellas pierden cualquier virtualidad jurídica, y aunque sean totalmente determinables con respecto al derecho, no creemos que alcancen a desnaturalizarse de las propias características de este, al punto de adquirir un carácter estrictamente patrimonial, como el catedrático afirma. En cualquier caso, la facultad o faceta objeto del contrato necesariamente siempre estará condicionada por formar parte del contenido del derecho de la personalidad ${ }^{38}$.

En este orden de cosas preferimos hablar, en palabras de Álvarez-Tabío Albo, de la creación de un nuevo derecho subjetivo - compuesto solo por algunas facultades del derecho de la personalidad - o de una suerte de sucesión constitutiva por medio del cual, surge un derecho derivado del mismo objeto que soporta el derecho madre, pero con su propia configuración y delimitación de carácter temporal, del cual será titular un nuevo sujeto, a favor del cual se hace la cesión de ciertas facultades inherentes al derecho originario, sin que ello implique el despojo del mismo ni la exclusividad de su uso a favor de otra persona. ${ }^{39}$

Podemos concluir que la disponibilidad parcial de los derechos de la personalidad, realizada de forma $\operatorname{concreta}^{40}$, no implica que

37 Todo parece indicar que no opina lo mismo con respecto al acto unilateral que permite la intromisión o la publicidad sin finalidad económica, pues no se explota poder jurídico alguno. Vid. Luis-Humberto Clavería Gosálbez, "Negocios jurídicos de disposición...”, op. cit., 50.

38 En este sentido es válido resaltar la regulación que realiza el Código Civil peruano en su artículo 15, el que denomina aprovechamiento de la imagen y la voz de la persona. Como se colige del nomen iuris de la norma, el legislador ha querido establecer una clara diferencia entre el derecho a la imagen y la voz de la persona y la posibilidad de aprovechamiento del mismo. Sin embargo, tal como hemos afirmado, es evidente que esta facultad está condicionada por la existencia del derecho de la personalidad al cual corresponde, sin que sea posible la desnaturalización de la misma. Cfr. art. 15 Código Civil de Perú.

39 Vid. A. M. Álvarez-Tabío Albo, "Los derechos al honor...", op. cit., 23.

40 Estas facultades no pueden ser cedidas indefinidamente en el tiempo ni a un número indeter- 
los mismos pierdan sus caracteres definitorios; al contrario, siguen siendo connaturales al hombre y pertenecen a este por su sola condición de persona humana. El acto jurídico de la disponibilidad no significa que se ha renunciado al derecho, ni que deje de acompañar la vida de su titular, sino que otras personas puedan servirse del derecho e incluso, en determinadas circunstancias, adoptar decisiones que impliquen los mismos; pero nunca en desmedro de su titular, lo que solo es posible si este así lo ha decidido.

En relación a la posible disponibilidad de los derechos de la personalidad, es claro que el artículo 38 del Código Civil cubano realiza un reconocimiento negativo de estos derechos; sin embargo, ello no constituye, desde nuestra consideración, una limitación para excluir la posibilidad de disponer de los derechos de la personalidad. Su regulación negativa obedece al momento histórico en que fue adoptado, de ahí que una interpretación evolutiva de la norma, que tome en cuenta el reconocimiento de la institución dentro del ordenamiento jurídico, el fin que tiene el precepto - de protección de los derechos inherentes a la personalidad- y su carácter no prohibitivo, nos permite sostener este criterio, como parte del propio ejercicio de estos.

Cuando hablamos de la disponibilidad de estos derechos, debemos tener presente tanto las regulaciones normativas que sobre los mismos se han realizado como las regulaciones que los propios particulares hayan tenido en cuenta en el ejercicio de la autonomía privada, principio del derecho que encuentra su positivización en la norma sustantiva cubana en su artículo $312^{41}$. Sin embargo, en este punto son dos las causas que inciden en la posibilidad de la aplicación de la figura; la ausencia de una regulación expresa que establezca la delimitación de los derechos de la personalidad, a partir del reconocimiento del contenido esencial de cada uno, y en consecuencia, la carencia de los límites de estos, los cuales, tal como reza el propio artículo constituirían la excepción a cualquier pacto, cláusula y condición que las partes tuvieran por conveniente establecer.

minado de personas, lo cual no excluye la plena titularidad del derecho en el futuro. Sustentada en la libertad individual, la disponibilidad siempre debe servir a la realización de los intereses que el propio derecho en sí mismo protege y defiende. El interés de su titular, su dignidad y la ley son sus límites.

41 Art. 312, Ley 59/1987 de 16 de julio Código Civil de la República de Cuba. 
Estas ausencias reafirman la posición anteriormente sostenida desde una visión de lege data. Solo los jueces pueden determinar el equilibrio entre el respeto a la libertad individual y los derechos de la personalidad. La facultad de disposición no sería objeto de pronunciamiento y delimitación, por parte del tribunal, hasta que no existiera litis. Coincidimos también con la posición defendida sobre la formulación de los derechos de la personalidad, desde una visión de lege ferenda. Esta solo será posible a partir del reconocimiento del contenido esencial y la facultad de disponer de los mismos, en correspondencia con las limitaciones que le son propias, lo cual servirá no solo para establecer los límites de disposición, sino también de complemento, ante la ausencia por parte del titular, de previsiones con respecto al derecho en disposición.

A partir de lo anteriormente expuesto, podemos concluir que existe un margen para la voluntad permitido por el derecho en el cual se puede disponer de algunas facetas o facultades de los derechos de la personalidad, sin que ello signifique una vulneración de estos ni de la dignidad humana. Margen en el que sin lugar a dudas cabe la posibilidad de autorizar la representación voluntaria de estos derechos, en respeto de la libertad y autonomía de la voluntad. Sin embargo, lo cierto es que no podemos referirnos a esta posibilidad en los mismos términos que la representación de cualquier acto patrimonial; una vez más las características de estos derechos y su carácter personalísimo condicionan esta posibilidad.

\section{LA REPRESENTACIÓN DE LOS DERECHOS DE LA PERSONALIDAD, ESPECIAL REFERENCIA EN LOS CASOS DE LAS VOLUNTADES ANTICIPADAS}

Siendo prácticamente imposible establecer un modelo de representación para todos los derechos de la personalidad, teniendo en cuenta el carácter excepcional de la misma, que por demás no puede ser aplicado a todos los derechos de la misma forma, explicaremos algunas de las características de la representación voluntaria de estos a partir del derecho a la integridad física, y específicamente su materialización en las llamadas voluntades anticipadas. 
Las voluntades anticipadas, al igual que el consentimiento informado, son fruto del replanteamiento de la forma de concebir la relación médico-paciente ${ }^{42}$. Constituyen expresión del proceso de transformación de esta relación que abandona la concepción paternalista del juramento hipocrático para ganar en horizontalidad, participación e interacción de los sujetos en ella implicados. Suponen, al decir del profesor Sánchez González, una exigencia ética, un nuevo ideal de autonomía y de racionalidad, una expresión de una nueva cultura de la información y del pluralismo, lo que expresado en otros términos no es más que el traslado de valores como la libertad, la igualdad y la dignidad a las ciencias médicas ${ }^{43}$ Los términos "voluntad anticipada" "44, "instrucciones previas", "declaración de voluntad vital anticipada" y "expresión anticipada de voluntades", se utilizan para definir el documento libremente redactado, en la forma establecida en la ley, por una persona en

42 Existe un consenso tanto desde el campo de las ciencias médicas como del derecho en cuanto a la concepción y viabilidad del consentimiento informado, como expresión de la autonomía del individuo en el campo médico-clínico. Aunque desde la propia significación del fenómeno, este puede ser analizado desde disímiles puntos de vistas, ello no conlleva un cercenamiento del mismo por razón de enfoque. Para el doctor Zamora Marín no es más que "un acto voluntario realizado libremente por un sujeto competente de acuerdo con la información adecuada, con gran competencia individual y de forma progresiva y la competencia del sujeto para recibir y procesar información y tomar decisiones, enriquecidas con la comprensión, el afecto, la solidaridad y el razonamiento científico del médico". Sin embargo, el profesor de medicina interna Alejandro Goic G. lo considera desde el punto de vista de la ética médica como "parte de la relación interpersonal, que al decir el profesor no deja de ser técnica, diagnóstico-terapéutica; se establece en la relación médico paciente, en la que el respeto a la condición propia de seres humanos tiene una categoría que sobrepasa con mucho una relación meramente profesional y en cierto modo la condiciona". Desde un punto de vista axiológico el profesor Sánchez González lo considera como "la aceptación de una intervención médica por un paciente, en forma libre, voluntaria y consciente, después que el médico le haya informado de la naturaleza de la intervención con sus riesgos y beneficios, asi como de las alternativas posibles con sus respectivos riesgos y beneficios siempre que esta decisión se haya realizado conforme a los valores y prioridades de su titular". Vid. René Zamora Marín, "Consentimiento Informado", Trabajo de curso del Diplomado de Bioética, Pontificia Universidad Católica de Chile; Goic G., Alejandro, Ética en la relación médico paciente, Cuadernos del Programa Regional de Bioética, No. 1 (sep., 1995); José Alberto Mainetti, "Calidad de la atención de la salud y los derechos del paciente: entre la evidencia y la autonomía", en Programa Regional de Bioética, Organización Panamericana de la Salud, Serie Publicaciones 2000.

43 Miguel A. Sánchez González, El consentimiento informado: Un derecho del enfermo y una forma distinta de tomar las decisiones, Cuadernos del Programa Regional de Bioética, No. 2 (abr., 1996).

44 Dentro del genérico concepto de voluntades anticipadas se conciben tres nuevas figuras jurídicas: las voluntades anticipadas en estricto sentido, la auto-tutela y los poderes preventivos. En un sentido estricto el término ha quedado solo para denominar al documento que expresa de forma anticipada los cuidados y tratamientos que se desea recibir llegado el caso de encontrarse la persona que lo otorga en situación de no poder expresar personalmente su voluntad. 
momentos de lucidez y capacidad, dirigido al responsable médico para el supuesto en que se encuentre privado de expresar su voluntad, con la finalidad de que se tengan en cuenta sus deseos o que otra persona le represente ante el médico ${ }^{45}$.

Similares conceptualizaciones, dentro de las que es posible la designación de un representante, han quedado debidamente reguladas $^{46}$ en el artículo 11 de la Ley 41/2002, de 14 de noviembre, básica reguladora de la autonomía del paciente y de derechos y obligaciones en materia de información y documentación clínica en el ordenamiento jurídico español ${ }^{47}$, y en el Decreto número 120, Ley de voluntad vital anticipada de los derechos de los enfermos en estado terminal del Estado de Michoacán de Ocampo, México ${ }^{48}$. Lo que implica la posibilidad que tiene un tercero de poder actuar en nombre de otro en la esfera médica, en la que sin lugar a dudas se ponen de manifiesto derechos de la personalidad tan importantes como la propia vida y la integridad física de la persona ${ }^{49}$. Sin

45 La cursiva es nuestra. Vid. José Luis Requero Ibáñez, "El testamento vital y las voluntades anticipadas. Aproximación al ordenamiento español" (digital)

46 En Cuba no existen disposiciones normativas en cuanto a las voluntades anticipadas, de lo que se colige que sea imposible que hablemos de representante en este sentido. El único referente normativo que tiene nuestro ordenamiento jurídico sobre el tema se haya en la Ley número 41, Ley de La Salud Pública de trece de julio de mil novecientos ochenta y tres, y solo con relación al consentimiento informado. En ella se establece la necesidad de que en los métodos de diagnóstico utilizados en la práctica médica, donde se apliquen los medios preventivo-curativos y de rehabilitación aprobados por el Ministerio de Salud Pública que impliquen riesgos para la salud de los pacientes, se realicen con la aprobación de estos, excepto en los menores de edad o personas con incapacidad mental, en cuyos supuestos se requiere la autorización del padre, madre, tutor, o representante legal en su caso; igual proceder debe de ser utilizado en las intervenciones quirúrgicas, procederes diagnósticos y terapéuticos con la excepción de aquellos casos de carácter urgente en los que peligre la vida del paciente. Vid. arts. 18 y 19, Ley No. 41/1983 de 13 de julio Ley de La Salud Pública.

47 Por el documento de instrucciones previas, una persona mayor de edad, capaz y libre, manifiesta anticipadamente su voluntad, con objeto de que esta se cumpla en el momento en que llegue a situaciones en cuyas circunstancias no sea capaz de expresarlos personalmente, sobre los cuidados y el tratamiento de su salud o, una vez llegado el fallecimiento, sobre el destino de su cuerpo o de los órganos del mismo. El otorgante del documento puede designar, además, un representante para que, llegado el caso, sirva como interlocutor suyo con el médico o el equipo sanitario para procurar el cumplimiento de las instrucciones previas. Instrucciones previas. Art. 11.1, Ley 41/2002, de 14 de noviembre, Básica reguladora de la autonomía del paciente y de derechos y obligaciones en materia de información y documentación clínica.

48 Los enfermos en estado terminal tienen los siguientes derechos: "IX. Designar representante legal o persona de su confianza, de acuerdo a los requisitos y procedimientos establecidos en la presente Ley, para el cumplimiento de los fines señalados en la misma"; Vid. art. 5, Decreto número 120, Ley de voluntad vital anticipada de los derechos de los enfermos en estado terminal del Estado de Michoacán de Ocampo, México, Periódico Oficial del Gobierno Constitucional del Estado de Michoacán de Ocampo, Tomo 147, publicado el lunes 21 de septiembre del 2009.

49 El artículo 9.3 de la Ley 41/2002, de 14 de noviembre, Básica reguladora de la autonomía del paciente y de derechos y obligaciones en materia de información y documentación clínica, 
embargo, ello no es una posibilidad exclusiva de esta institución; a criterio de Parra $^{50}$, en otras figuras como la auto-tutela y los poderes preventivos $^{51}$ también pueden existir este tipo de previsiones, en las cuales la relación representativa encuentra su base y fundamento en el vínculo de confianza y fidelidad entre representante y representado, relación que ostenta un carácter marcadamente personal.

En este caso, la disponibilidad de los derechos de la personalidad queda configurada en el propio documento que concibe la voluntad anticipada, medio por el cual se autoriza la representación y que por ende legitima la intromisión en la esfera personalísima. Surgen sin lugar a dudas múltiples interrogantes, especialmente a la hora de interpretar la voluntad de esa persona que en el momento de la adopción de las decisiones médicas no tiene plena capacidad para decidir las mismas. ¿Es el representante un mero ejecutor de la voluntad anticipada o puede decidir sobre la esfera personalísima ajena? ¿Cuáles son los límites en la formulación la voluntad del representado? ¿Es posible mantener esta representación aun y

establece que se otorgará el consentimiento por representación "a) Cuando el paciente no sea capaz de tomar decisiones, a criterio del médico responsable de la asistencia, o su estado físico o psíquico no le permita hacerse cargo de su situación. Si el paciente carece de representante legal, el consentimiento lo prestarán las personas vinculadas a él por razones familiares o de hecho. b) Cuando el paciente esté incapacitado legalmente. c) Cuando el paciente menor de edad no sea capaz intelectual ni emocionalmente de comprender el alcance de la intervención. En este caso, el consentimiento lo dará el representante legal del menor después de haber escuchado su opinión si tiene doce años cumplidos. Cuando se trate de menores no incapaces ni incapacitados, pero emancipados o con dieciséis años cumplidos, no cabe prestar el consentimiento por representación. Sin embargo, en caso de actuación de grave riesgo, según el criterio del facultativo, los padres serán informados y su opinión será tenida en cuenta para la toma de la decisión correspondiente". Si bien el artículo 9.3a) nos habla del representante legal, todo nos conlleva a suponer que ciertamente no se ha utilizado el término en el sentido del tipo de representación legal, sino en la designación del representante voluntario realizada en el documento de las directivas anticipadas, tal como lo prevé la propia norma posteriormente en el artículo 11, además que, strictus sensus el término de representante legal solo puede ser utilizado conforme el propio apartado lo establece en su inciso b), cuando existe incapacitación legal o se ha autorizado un curador, en caso contrario, no se corresponde dicha designación con el supuesto contemplado en el propio apartado a), situaciones que para nada tienen que necesariamente coincidir con la incapacidad.

50 María Ángeles Parra, "Voluntades anticipadas (autonomía personal: Voluntades anticipadas, autotutela y poderes preventivos)", en Ponencias del XV Encuentros del foro de Derecho aragonés. Disponible en www.eljusticiadearagon.com/..._n002863Voluntades\%20anticipadas. pdf consultado (12 de diciembre del 2010).

51 Sobre el contenido de los poderes preventivos cfr. Jorge Luis Ordelin Font y Raúl José Vega Cardona,. Los poderes preventivos. Breves apuntes para su aplicación dentro del ordenamiento jurídico cubanoRevista del Instituto de Derecho e Integración, No. 7, año 4, Colegio de Escribanos de la provincia de Santa Fe, Segunda Circunscripción, Rosario, Argentina (2012). 
cuando se haya decidido la incapacitación del representante y la imposibilidad de revocar la autorización?

Como supuesto de disponibilidad parcial de los derechos de la personalidad no basta solo con que el consentimiento sea expreso, sino también que sea interpretado en forma estricta ${ }^{52}$; sin embargo, ello no implica que el representante de la voluntad anticipada sea un mero ejecutor, velador o nuncio, pues con ello contradice la necesidad de la figura ${ }^{53}$. En este aspecto Parra, citando a otros autores ${ }^{54}$, explica la posibilidad de que el representante pueda sustituir la voluntad no expresada por el paciente, lo que se deriva, a juicio de la autora, del respeto a la voluntad del mismo, que exige que la actuación del representante se limite a aclarar situaciones o a cubrir lagunas o deficiencias del documento. En contra de esta postura, Berrocal Lanzarot reconoce en el representante uno de los destinatarios del documento de voluntades anticipadas en unión con el médico responsable y el centro sanitario, pero solo considerado como un medio hábil de expresión de la voluntad del paciente, que conoce mejor y de primera mano la voluntad real del paciente en los momentos anteriores a la intervención. Para la autora, en el supuesto de que no exista correspondencia entre el supuesto de hecho previsto por el sujeto y la situación real que se produce, al no existir ninguna instrucción previa para tal situación estaríamos ante un supuesto de consentimiento por representación, que debe ser prohibido en pos de evitar la analogía contra vita.

Ciertamente, cuando no existe correspondencia entre el supuesto que comprende la voluntad anticipada y la situación real del

52 Cfr. J. César Rivera, “Actos de disposición de los derechos de la personalidad...”, op. cit., 92 y ss.

53 Ello no es una opinión unánime en la doctrina; para Lamber el hecho de que no se defina la naturaleza jurídica de las directivas anticipadas es un acierto, porque entonces estamos en un campo extraño a la representación voluntaria, y podemos profundizar la tesis de la declaración como propia, que transmite el autorizado como un simple "nuncio" del derecho romano, portador de un mensaje, que no puede exceder su contenido expreso. Cfr. Rubén Augusto Lamber, Declaraciones sobre la muerte digna, los derechos del paciente y las previsiones para el supuesto de incapacidad en el derecho argentino. Disponible en http://www.bioetica.org/cuadernos/ contenidos/lamber.htm (9 de febrero del 2012). En este sentido, para Diez-Picazo no existe diferencia sustancial entre nuncio y el representante, vid. L. Diez-Picazo, La representación en el Derecho Privado, op. cit., 53 y ss.

54 Requero, Domínguez Luemo, Barral Viñals, cit. pos M. Á. Parra, "Voluntades anticipadas...", op. cit., 84.

55 Ana Isabel Berrocal Lanzarot, El valor de la autonomía del paciente en la ley 41/2002, del 14 de noviembre, reguladora de los derechos y deberes de los pacientes, p. 140. Disponible en www. aeds.org/ponencias/Ana\%20Berrocal.pdf (9 de febrero del 2012). 
paciente, aquella es como si fuera inexistente ${ }^{56}$. Sin embargo, esta inexistencia solo queda contemplada en cuanto al contenido de la voluntad anticipada; no sería descabellado entonces preguntarnos si se debería tener en cuenta la designación del representante como la persona que ha tenido en cuenta el paciente para la adopción de las decisiones médicas, aunque sean para un supuesto clínico diferente. Creemos que debe de primar la voluntad del paciente y si este ha elegido a una persona determinada, en base a su confianza, aunque no sea para el supuesto real, esta decisión debe ser respetada por la práctica médica.

Aunque respetado, discrepamos del criterio de la autora anteriormente mencionado, en cuanto a la consideración del representante exclusivamente como un medio hábil de expresión de la voluntad del paciente. Como bien la propia autora plantea, en ocasiones es necesario acudir al representante para conocer la voluntad real del paciente en los momentos anteriores a la intervención. ¿Pero termina ahí la actuación del representante? ¿Cuál es el alcance de la voluntad manifestada por este? Es única y exclusivamente la interpretación de la voluntad del paciente-representado ¿Dónde termina la interpretación de la voluntad del paciente-representado y dónde se inicia la manifestación de voluntad del representante?

Por muy preciso que sea el documento de las voluntades anticipadas, es imposible que prevea todos los aspectos concernientes al tratamiento médico. Es la voluntad del interesado en la representación lo que define el espectro de la misma, dígase sujetos y facultades, determinando el alcance de las mismas en dependencia de sus intereses.

La formulación de la declaración de voluntad por parte del representante implica que este tiene que formar y emitir una declaración de voluntad suya, aunque sea realizada en nombre y por cuenta del representado, teniendo un margen más o menos amplio de libertad, donde se debe respetar la voluntad expresada que refleja el interés digno de protección jurídica, que no es más que la forma a partir

56 No serán aplicadas las instrucciones previas contrarias al ordenamiento jurídico, a la lex artis, ni las que no se correspondan con el supuesto de hecho que el interesado haya previsto en el momento de manifestarlas. En la historia clínica del paciente quedará constancia razonada de las anotaciones relacionadas con estas previsiones. Vid. art. 11.3, Ley 41/2002, de 14 de noviembre, Básica reguladora de la autonomía del paciente y de derechos y obligaciones en materia de información y documentación clínica. 
de la cual el paciente, como ser portador de valores, delimita su posición ante los tratamientos médicos.

Solo tomemos en cuenta el hecho de que, para emitir un documento como el de las voluntades anticipadas, es necesario un nivel determinado de información sobre el diagnóstico y las posibles alternativas de tratamiento médico. El avance científico técnico de la medicina, sin lugar a dudas, puede provocar un cierto desfase entre la toma de la decisión y las posibilidades de tratamiento de la enfermedad, incluido su diagnóstico. Volvemos, una vez más, al centro de nuestra disquisición, desechar la voluntad anticipada por no expresar las decisiones específicas para cada supuesto fáctico que ha tenido en cuenta el paciente a la hora de otorgar el documento y designar un representante, o concebir que este pueda adoptar decisiones al respecto en un margen más o menos amplio, en relación con la enfermedad de referencia. Decisiones que por demás, en cualquier caso, deberán ser tomadas por otra persona que no es el titular de los derechos de la personalidad, dígase familiares más allegados o el propio médico. Una vez más coincidimos en la primera opción, por mucho que intentemos evadir el tema: en las voluntades anticipadas existe representación voluntaria, restringida y excepcional, pero representación.

Sin lugar a dudas aceptar la posición que hemos venido defendiendo significa responder a otros dilemas. ¿Cuáles son los límites que tiene la persona para disponer por medio de la representación sobre el tratamiento médico? ¿Cuáles son los límites que tiene el representado para intervenir en una esfera jurídica ajena tan personal como los derechos de la personalidad?

Los deberes de fidelidad, lealtad y de realización de la gestión encomendada ${ }^{57}$ que rigen cualquier actividad representativa imponen al representante la necesidad de comportarse de acuerdo con la confianza depositada, desenvolviendo la actividad de gestión de acuerdo con unas determinadas directrices emanadas de las instrucciones del principal, es decir, de acuerdo al interés del dominus, que no es otra cosa que el paciente.

Los límites a la voluntad de disponer, como anteriormente hemos expuesto, lo constituye el respeto a la dignidad del individuo ma-

57 L. Diez-Picazo, La representación en el Derecho Privado, op. cit., 56. 
terializado en el contenido esencial del derecho positivizado en la norma imperativa, así como las instrucciones de la buena práctica clínica. En caso de no existir regulación sobre el contenido esencial del derecho, como sucede en el ordenamiento jurídico cubano, solo la dignidad del ser humano y las instrucciones de la buena práctica clínica se erigen como valladares infranqueables para la autonomía del paciente. Por su parte, el representante encontrará estos límites en las directrices oportunamente establecidas, en base a la voluntad del representado, así como en el interés digno de protección jurídica que se constata de la interpretación de las referidas directrices. No en vano se ha planteado que en casos de oscuridad o desfase, debe entenderse que junto a la voluntad del otorgante concurre el principio de beneficio del paciente ${ }^{58}$.

Consustancial a la institución que venimos tratando es la posibilidad de la revocación de la voluntad anticipada cuando la persona es incapacitada. La posición adoptada implica la subsistencia o no de la designación del representante para el ámbito sanitario. Existe consenso en concebir la posibilidad de la revocación como complemento de la protección al derecho de la personalidad sobre el cual se ha dispuesto. Sin embargo, este consenso se rompe cuando la persona es incapacitada, y por lo tanto no puede decidir sobre la pertinencia de la gestión desarrollada por el representante sanitario. Se rompe así la necesaria relación en cuanto a los deberes de comunicación, consulta e información que debe regir cualquier relación representativa. Una vez más, abogamos por el respeto de la autonomía de la voluntad del paciente sobre cualquier otra decisión que pueda ser tomada, siempre y cuando se respeten los límites a esta autonomía anteriormente apuntados.

La incapacidad de obrar del paciente implica necesariamente que otra persona, en su lugar, deberá adoptar las decisiones clínicas correspondientes ${ }^{59}$. Si de todas formas procede la representación,

58 J. L. Requero Ibáñez, "El testamento vital y...", op. cit., 15. Este principio ha quedado positivizado en el ordenamiento jurídico español en el artículo 9.5 Ley 41/2002, de 14 de noviembre, Básica reguladora de la autonomía del paciente y de derechos y obligaciones en materia de información y documentación clínica. "La prestación del consentimiento por representación será adecuada a las circunstancias y proporcionada a las necesidades que haya que atender, siempre en favor del paciente y con respeto a su dignidad personal. El paciente participará en la medida de lo posible en la toma de decisiones a lo largo del proceso sanitario".

59 Cfr. arts. 6 y 7 Convenio Europeo sobre los derechos humanos y la biomedicina: Convenio para la protección de los derechos humanos y la dignidad del ser humano con respecto a las 
aunque sea de tipo legal, y por tanto la intromisión en la esfera personal del incapacitado por otros sujetos, sin lugar a dudas debe prevalecer la designación del sujeto que fue tenido en cuenta cuando la persona gozaba de plena capacidad.

Es decir, si el supuesto de la incapacidad va a provocar el mismo efecto en el ejercicio de los derechos de la personalidad, al existir un tercero que decida por el incapacitado, es obvio que debemos de preferir aquella designación que ha tenido su causa en la voluntad del titular de los derechos de la personalidad y no aquella que tiene su causa en la voluntad legal. En este aspecto coincidimos con Parra cuando concibe la posibilidad de sostener este nombramiento incluso cuando se ha designado un tutor por el concreto ámbito de actuación del representante. ${ }^{60}$ Similar criterio hemos sostenido oportunamente cuando analizamos la subsistencia de los poderes preventivos y el nombramiento de un tutor. ${ }^{61}$

aplicaciones de la Biología y la Medicina, Oviedo (Asturias), 4 de abril de 1997. Art. 9.3. b) Ley 41/2002, de 14 de noviembre, Básica reguladora de la autonomía del paciente y de derechos y obligaciones en materia de información y documentación clínica.

60 M. Á. Parra, "Voluntades anticipadas...", op. cit.,84.

61 Cfr. J. L. Ordelin Font \& R. J. Vega Cardona, "Los poderes preventivos...”, op. cit. 


\section{CONSIDERACIONES FINALES}

En un tema tan polémico como el que nos ocupa no está dada aún la última palabra; múltiples disyuntivas surgen en un contexto en el cual el ordenamiento jurídico debe velar por el fin ontológico del hombre. Para nada hemos querido ofrecer pautas o criterios irrefutables, todo lo contrario, como un ejercicio propio de esa dignidad que hemos invocado en más de una ocasión en este texto, preferimos y abogamos por el pluralismo de las ideas, decisiones y principios que sustenten una contradicción científica que, como esta, conlleven al debate.

Reafirmamos nuestra posición en cuanto a concebir los derechos de la personalidad como medios para la realización del individuo en el ordenamiento jurídico cubano, cuyo interés digno de tutela jurídica - porque permite esa realización — puede verse satisfecho con el actuar positivo que implica la disponibilidad parcial de los derechos de la personalidad, sin que ello conlleve la pérdida de sus caracteres definitorios, lo que se traduce en un margen para la voluntad de sus titulares en la que es posible la representación voluntaria de los mismos, en dependencia de las características de cada uno de estos derechos y de forma excepcional. Esta es también otra vía de permitir la realización del individuo siempre que no vaya en desmedro de los límites de la dignidad humana.

El derecho civil de este siglo, al tener como su centro de estudio la persona, está llamado a redimensionarse en cada contexto, para responder a las exigencias de un mundo en el que por momentos parece que la dignidad del hombre debe ceder para dar paso a los adelantos de la ciencia y la técnica. Ello solo será posible si, como ciencia, el derecho y especialmente el derecho civil, no son capaces de replantearse sus milenarios dogmas. Continuemos con el debate... 


\section{BIBLIOGRAFÍA}

\section{Doctrina}

Actas del Cuarto Congreso Nacional de Derecho Civil, 22-27 de septiembre de 1969, Celebración del Centenario del Código Civil, Tomo I, Córdoba (1971).

Alejandro Goic G., Ética en la relación médico paciente, Cuadernos del Programa Regional de Bioética, No. 1 (sep., 1995).

Alonso Pérez Mariano, "Reflexiones sobre el concepto y valor de la persona en el Derecho civil de España", en Anuario de Derecho Civil, Tomo XXXVI, fascículo III (oct.-dic., 1983).

Ana Isabel Berrocal Lanzarot, El valor de la autonomía del paciente en la ley 41/2002, del 14 de noviembre, reguladora de los derechos y deberes de los pacientes, p. 140. Disponible en www.aeds.org/ponencias/Ana\%20Berrocal.pdf ( 9 de febrero del 2012).

Ana María Álvarez-Tabío Albo, "Los derechos al honor, la intimidad personal y familiar y la propia imagen como límites a las libertades de información y expresión", Tesis presentada en opción al grado científico de Doctor en Ciencias Jurídicas, La Habana (2008).

Ana María Álvarez-Tabío Albo, Los derechos inherentes a la personalidad, Boletín $O N B C$, No. 16 (jul.-sep. 2004)

Caridad del Carmen Valdés Díaz, Acerca del ejercicio de las personas discapacitadas. Una aproximación desde la realidad cubana. Disponible en www.revistapersona. com.ar/Persona58/58Valdes.htm (9 de febrero del 2012).

, "Comentario al artículo 38 del Código Civil", en Comentarios al Código Civil cubano, Tomo I, Disposiciones generales, Libro I, Relación jurídica, Leonardo B. Pérez Gallardo (dir. en prensa).

Derechos inherentes a la personalidad, Bioética y Derecho de Familia. Algunas reflexiones jurídicas con especial referencia a la normativa cubana (digital).

Carlos Fernández Sessarego, Persona, personalidad, capacidad, sujeto de derecho: Un reiterado y necesario deslinde conceptual en el umbral del siglo XXI. Disponible en http://www.revistapersona.com.ar/Persona24/24FernandezSessarego.htm (9 de febrero del 2012).

Federico De Castro, "Los llamados derechos de la personalidad. Dos estudios provisionales", en Anuario de Derecho Civil, Tomo XII, fascículo IV, Instituto Nacional de Estudios Jurídicos, Servicio de Publicaciones (oct.-dic., 1959).

Gisela María Pérez Fuentes, Evolución doctrinal, legislativa y jurisprudencial de los derechos de la personalidad y el daño moral en España, Revista de Derecho Privado, No. 8, Instituto de Investigaciones Jurídicas de la unam, México.

Guido Fassó, Historia de la Filosofía del Derecho, Tomo 2, La Edad Moderna, $3^{\mathrm{a}}$ ed., Ediciones Pirámide, Madrid (1982).

Iñigo De Miguel Beriain, "Consideraciones sobre el concepto de dignidad humana", en Anuario de Filosofía del Derecho, Nueva Época, Tomo XXI (2004). 
J. Pérez Royo, Curso de Derecho constitucional, $4^{\mathrm{a}}$ ed., Editorial Marcial Pons S.A., Madrid (1997).

Jesús. Alfaro Águila-Real, “Autonomía privada y derechos fundamentales”, en Anuario de Derecho Civil, Tomo XLVI, fascículo I (ene.-mar., 1993).

Jorge Luis Ordelin Font \& Raúl José Vega Cardona, Los poderes preventivos. Breves apuntes para su aplicación dentro del ordenamiento jurídico cubano, 1 Revista del Instituto de Derecho e Integración, No. 7, año 4, Colegio de Escribanos de la provincia de Santa Fe, Segunda Circunscripción, Rosario, Argentina (2012).

José Alberto Mainetti, "Calidad de la atención de la salud y los derechos del paciente: entre la evidencia y la autonomía", en Programa Regional de Bioética, Organización Panamericana de la Salud, Serie Publicaciones (2000).

José Asensi Sabater, Constitucionalismo y Derecho constitucional-Materiales para una Introducción, Tirant lo Blanch, Valencia (1986).

José Castán Tobeñas, Derecho Civil español, común y foral, tomo 1, Reus, Madrid (1987).

José Javier Hualde Sánchez, “Los derechos de la personalidad”, en Manual de Derecho Civil, Introducción y derecho de la persona, Lluis Puig I. Ferriol et ál., Marcial Pons, Ediciones Jurídicas y Sociales, Madrid (1997).

José Javier López Jacoiste, “Una aproximación tópica a los derechos de la personalidad”, en Anuario de Derecho Civil, Tomo XXXIX, fascículo IV (oct.-dic., 1986).

José Manuel Márquez Ruiz, 『Comienzo y fin de la personalidad邓, en Noticias Jurídicas, abril del 2004. Disponible en: www.sentencias.jurídicas.es (4 de enero del 2010).

Josef Hupka, La representación voluntaria en los negocios jurídicos, Revista de Derecho Privado, Madrid (1930).

Julio César Rivera, Actos de disposición de los derechos de la personalidad: actuación por los representantes legales, Revista de Derecho Privado y Comunitario, No. 6, Rubinzal-Culzoni, 91 (1994).

Justina M. Díaz, Derechos personalísimos en la Bioética, Facultad de Derecho de la Universidad de Buenos Aires. Disponible en portalacademico.derecho.uba.ar/.../ asig_catedras_doc_curr.asp? consultado el 12 de febrero de 2012.

Luis Diez-Picazo, La representación en el Derecho Privado, Civitas, Madrid (1979).

Luis Moisset de Espanés \& María del Pilar Hiruela de Fernández, "Derechos de la personalidad”, Artículos de la Academia de Ciencias Jurídicas de Córdoba, Argentina. Disponible en www.acaderc.org.ar/doctrina/articulos/ artintimidacion/at download/file\&\#8206; consultado el 12 de febrero de 2012.

Luis Recasens Fiches, Estudios de Filosofía del Derecho, tomo I, Unión Tipográfica Editorial Hispano-Americano, México, 380 (1946).

, Vida humana, Sociedad y Derecho, Biblioteca Virtual Universal (2003).

Luis-Humberto Clavería Gosálbez, "Negocios jurídicos de disposición sobre los derechos al honor, la intimidad y la propia imagen", en Anuario de Derecho Civil, Tomo XLVII, fascículo III, 32 (jul.-sep., 1994).

, "Reflexiones sobre los derechos de la personalidad a la luz de la Ley Orgánica 1-1982, de 5 de mayo", en Anuario de Derecho Civil, Tomo XXXVI, 
fascículo III (oct.-dic., 1983).

María Ángeles Parra, "Voluntades anticipadas (autonomía personal: Voluntades anticipadas, autotutela y poderes preventivos)", en Ponencias del XV Encuentros del foro de Derecho aragonés. Disponible en www.eljusticiadearagon.com/..._ n002863Voluntades\%20anticipadas.pdf consultado (12 de diciembre del 2010).

María Milagrosa Díaz Magrans, "La persona individual”, en Derecho Civil. Parte General, Caridad del C. Valdés Díaz (coord.), Félix Varela, La Habana (2002).

René Zamora Marín, "Consentimiento Informado", Trabajo de curso del Diplomado de Bioética, Pontificia Universidad Católica de Chile. Disponible en www. colegiodentistas.cl/portal/images/stories/pdf/ColeccionBioetica.pdf\&\#8206; consultado el 12 de febrero de 2012.

Rubén Augusto Lamber, Declaraciones sobre la muerte digna, los derechos del paciente y las previsiones para el supuesto de incapacidad en el derecho argentino. Disponible en http://www.bioetica.org/cuadernos/contenidos/lamber.htm (9 de febrero del 2012).

Vicente Rapa Álvarez, La relación jurídica. Categoría esencial en el nuevo Código Civil, Revista Jurídica, No. 19, año VI (abr.-jun., 1988).

\section{Fuentes legales}

Anteproyecto del Código Civil cubano. Comisión de Asuntos Jurídicos y Constitucionales de la Asamblea Nacional del Poder Popular, febrero de 1979.

Anteproyecto del Código Civil cubano, Comisión de Asuntos Jurídicos y Constitucionales de la Asamblea Nacional del Poder Popular, agosto de 1979.

Anteproyecto del Código Civil cubano, Comisión de Asuntos Jurídicos y Constitucionales de la Asamblea Nacional del Poder Popular, febrero de 1985.

Código Civil de Perú. Decreto Legislativo № 295, promulgado el 24 de julio de 1984, publicado el 25 de julio de 1984 y vigente a partir del 14 de noviembre de 1984 .

Constitución de la República de Cuba. Aprobada el 24 de febrero de 1976, modificada en 1978, 1992 y 2002.

Decreto No. 120, Ley de voluntad vital anticipada de los derechos de los enfermos en estado terminal del Estado de Michoacán de Ocampo, México. Periódico Oficial del Gobierno Constitucional del Estado de Michoacán de Ocampo, Tomo 147, publicado el lunes 21 de septiembre del 2009.

Código Civil de Portugal. Decreto-Ley No. 47 344, de 25 de noviembre de 1966. Actualizado por Decreto-Ley 323 de 17 de diciembre de 2001.

Ley 41/2002, de 14 de noviembre, Básica reguladora de la autonomía del paciente y de derechos y obligaciones en materia de información y documentación clínica.

Ley 59/1987 de 16 de julio. Código Civil de la República de Cuba.

Ley No. 10.406, de 10 de enero de 2002. Novo Código Civil Brasileiro.

Ley No. 41/1983 de 13 de julio. Ley de La Salud Pública. 
Ley Orgánica número 1/1982 de 5 de mayo. De protección civil del derecho al honor, a la intimidad personal y familiar y a la propia imagen.

\section{Fuentes jurisprudenciales}

Sentencia No. 513 de 29 de diciembre de 2011. Único considerando. Ponente Acosta Ricart. 
